This item was submitted to Loughborough's Research Repository by the author.

Items in Figshare are protected by copyright, with all rights reserved, unless otherwise indicated.

\title{
Structure mechanical modeling of thin-walled closed- section composite beams, part 2: multi-cell cross section
}

PLEASE CITE THE PUBLISHED VERSION

https://doi.org/10.1016/j.compstruct.2014.03.002

PUBLISHER

(c) Elsevier

VERSION

AM (Accepted Manuscript)

\section{PUBLISHER STATEMENT}

This work is made available according to the conditions of the Creative Commons Attribution-NonCommercialNoDerivatives 4.0 International (CC BY-NC-ND 4.0) licence. Full details of this licence are available at: https://creativecommons.org/licenses/by-nc-nd/4.0/

\section{LICENCE}

CC BY-NC-ND 4.0

\section{REPOSITORY RECORD}

Wang, Simon, and Chenyu Zhang. 2017. "Structure Mechanical Modeling of Thin-walled Closed- Section Composite Beams, Part 2: Multi-cell Cross Section”. figshare. https://hdl.handle.net/2134/26514. 


\title{
Structure mechanical modeling of thin-walled closed- section composite beams, part 2: multi-cell cross section
}

\author{
S Wang*, C Zhang \\ Department of Aeronutical and Automotive Enigneering \\ Loughborough University \\ Loughborough, Leicestershire, LE11 3TU, UK \\ *e-mail: S.Wang@lboro.ac.uk, \\ *Corresponding author. Tel. : +44 1509227252
}

Key words: Closed-section, Composite beams, Multi-cell, Thin-walled

\begin{abstract}
The methodology used in part 1 [1] of the work for single-cell thin-walled closedsection composite beams is extended to multi-cell thin-walled closed-section composite beams. The effect of material anisotropies is fully considered on the mid-surface shear strain of all the cross sectional members including skin walls and internal members. Numerical comparisons with ABAQUS finite element simulations are performed for three-cell box and elliptical beams with a variety of laminate layups under various loading conditions and excellent agreements are observed. Significant deficiency of some existing models are shown.
\end{abstract}

\section{Introduction}

An accurate structure mechanical model has been developed in part 1 [1] of the work for TWCSCBs with single-cell cross sections. In this part 2, the model is extended to TWCSCBs with multi-cell cross sections which are much more popular in several industrial sectors. The extension will involve more complex analytical operations than that for TWCSCBs with single-cell cross sections. All the kinematic developments remain the same and are not repeated here. However, details will be presented here to determine the local shell wall axial warping displacement, the mid-surface shear strain and the global beam stiffness matrix.

\section{The TWCSCBs model in [2-4]}

Fig. 1 shows the multi-cell cross section of a TWCSCB with its shear flow diagram. Although it is in a relatively simple one-direction multi-cell arrangement, the principle for the development of present 1-D TWCSCB modelling will be thoroughly demonstrated and remains the same for any arbitrary multi-cell arrangements.

Eq. (13) in part 1 of the work [1] gives the local shell wall mid-surface warping displacement $\bar{w}_{\omega}(s, z)$ as 


$$
\bar{w}_{\omega}(s, z)=-\Phi^{\prime}(z) \int_{0}^{s} r(s) d s+\int_{0}^{s} \bar{\gamma}_{s z} d s+\bar{w}_{\omega}(0, z)
$$

with $\bar{w}_{\omega}(0, z)=C^{-1} \oint\left[\Phi^{\prime}(z) \int_{0}^{s} r(s) d s-\int_{0}^{s} \bar{\gamma}_{s z} d s\right] d s$ and $C=\oint d s$. Note that the circular integration symbol $\oint$ denotes an integration over the whole cross section perimeter including both the skin and internal shell walls and starting point $s=0$ is arbitrary. It is seen from Eq. (1) that the shell wall mid-surface shear strain $\bar{\gamma}_{s z}$ needs to be determined first in order to determine the shell wall mid-surface axial warping displacement $\bar{w}_{\omega}(s, z)$. Applying Eq. (1) to any one complete cell, e.g. the $R_{t h}$ cell 1-2-3-4-1 as shown in Fig. 1, gives

$$
\oint_{R} \bar{\gamma}_{s z} d s=2 A_{e R} \Phi^{\prime}(z)
$$

where $2 A_{e R}=\oint_{R} r d s$ with $A_{e R}$ being the enclosed area by the $R_{t h}$ cell. In order to determine $\bar{\gamma}_{s z}$, Librescu and Song [2] assumes a constant shear flow $q_{R}$ developed within each cell under the St.Venent pure torque. Therefore, the resultant shearing force due to torsion on the four walls of the $R_{t h}$ cell are $N_{s z T}^{12}=q_{R}, N_{s z T}^{23}=q_{R}-q_{R-1}, N_{s z T}^{34}=q_{R}, N_{s z T}^{41}=q_{R}-q_{R+1}$, respectively. Further, the work [2] makes the same treatment as that for single-cell cross section. That is, $N_{S Z} \approx N_{s z T}=G(s, z) t(s, z) \bar{\gamma}_{s z}(s, z)$ where $G(s, z)$ is called the equivalent shear modulus and $t(s, z)$ is the thickness of the shell wall. However, it is not reported in the work [2] how to determine the equivalent shear modulus $G(s, z)$ in the case of generally laminated composite materials. Now, using the above two assumptions Eq. (2) becomes,

$$
\Phi^{\prime}(z)=\frac{1}{2 A_{e R}}\left[q_{R} \delta_{12}+\left(q_{R}-q_{R-1}\right) \delta_{23}+q_{R} \delta_{34}+\left(q_{R}-q_{R+1}\right) \delta_{41}\right]
$$

where

$$
\delta_{i j}=\int_{i}^{j}(d s / G t)
$$

This can be rearranged as:

$$
\Phi^{\prime}(z)=\frac{1}{2 A_{e R}}\left(-q_{R-1} \delta_{R, R-1}+q_{R} \delta_{R, R}-q_{R+1} \delta_{R, R+1}\right)
$$

where

$$
\begin{gathered}
\delta_{R, R-1}=\int_{R, R-1}(d s / G t) \\
\delta_{R, R}=\oint_{R, R}(d s / G t)
\end{gathered}
$$




$$
\delta_{R, R+1}=\int_{R, R+1}(d s / G t)
$$

$\delta_{R, R-1}$ represents the integration on the wall bounded by the $R_{t h}$ cell and the $(R-1)_{t h}$ cell; $\delta_{R, R}$ denotes the closed integration on the $R_{t h}$ cell and $\delta_{R, R+1}$ represents the integration on the wall bounded by the $R_{t h}$ cell and the $(R+1)_{t h}$ cell. Assembling Eq. (4) for all the $N$ cells shown in Fig. 1 gives

$$
[H]\{q\}=\{I\} \Phi^{\prime}
$$

where

$$
\begin{gathered}
\{q\}=\left\{\begin{array}{lllllll}
q_{1} & q_{2} & \ldots & q_{R} & \ldots & q_{N-1} & q_{N}
\end{array}\right\}^{T} \\
\{I\}=\left\{\begin{array}{lllllll}
1 & 1 & \ldots & 1 & \ldots & 1 & 1
\end{array}\right\}^{T} \\
{[H]=\left[\begin{array}{cccccccccc}
H_{1,1} & -H_{1,2} & 0 & \ldots & \ldots & \ldots & \ldots & \ldots & 0 \\
-H_{2,1} & H_{2,2} & -H_{2,3} & 0 & \ldots & \ldots & \ldots & \ldots & 0 \\
0 & \ldots & \ldots & \ldots & \ldots & \ldots & \ldots & \ldots & 0 \\
0 & \ldots & 0 & -H_{R, R-1} & H_{R, R} & -H_{R, R+1} & 0 & \ldots & 0 \\
0 & \ldots & \ldots & \ldots & \ldots & \ldots & \ldots & \ldots & 0 \\
0 & \ldots & \ldots & \ldots & \ldots & \ldots & -H_{N-1, N-2} & H_{N-1, N-1} & -H_{N-1, N} \\
0 & \ldots & \ldots & \ldots & \ldots & \ldots & 0 & -H_{N, N-1} & H_{N, N}
\end{array}\right]}
\end{gathered}
$$

where the elements $H_{i, j}$ are expressed as:

$$
H_{i, j}=\frac{1}{2 A_{e i}} \delta_{i, j}
$$

From Eq. (5), the shear flow of each cell, as a function of sectional rate of twist, $\Phi^{\prime}(z)$, is given as

$$
\{q\}=\{J\} \Phi^{\prime}
$$

where:

$$
\{J\}=[H]^{-1}\{I\}
$$

Finally, the shear flow distribution in each wall can be calculated as:

$$
\left\{\begin{array}{lllllllll}
q_{1} & q_{2,1} & \ldots & q_{R} & q_{R+1, R} & \ldots & q_{N, N-1} & q_{N}
\end{array}\right\}^{T}=\left\{\begin{array}{lllllllll}
J_{1} & J_{2}-J_{1} & \ldots & J_{R} & J_{R+1}-J_{R} & \ldots & J_{N}-J_{N-1} & J_{N}
\end{array}\right\}^{T} \Phi^{\prime}
$$

where the subscript of $R$ denotes the walls of the $R_{t h}$ cell that are not bounded with any other cells, e.g. the wall 1-2 and 3-4 in Fig. 1. Whereas the subscript of $R+1, R$ denotes the wall bounded by $(R+1)_{t h}$ and $R_{t h}$ cells, for example the wall 4-1 in Fig. 1 . By using the earlier assumption $N_{S Z} \approx N_{s z T}=G(s, z) t(s, z) \bar{\gamma}_{s z}(s, z)$ the distribution of shell wall mid-surface shear 
strain for a multi-cell section in the work [2] becomes:

$$
\begin{aligned}
& \left\{\begin{array}{lllllllll}
\bar{\gamma}_{s z}^{1} & \bar{\gamma}_{s z}^{2,1} & \ldots & \bar{\gamma}_{s z}^{R} & \bar{\gamma}_{s z}^{R+1, R} & \ldots & \bar{\gamma}_{s z}^{N, N-1} & \bar{\gamma}_{s z}^{N}
\end{array}\right\}^{T} \\
& =\left\{\begin{array}{l}
J_{1} /(G t)_{1}\left(J_{2}-J_{1}\right) /(G t)_{2,1} \ldots J_{R} /(G t)_{R}\left(J_{R+1}-J_{R}\right) /(G t)_{R+1, R} \cdots \\
\left(J_{N}-J_{N-1}\right) /(G t)_{N, N-1} J_{N} /(G t)_{N}
\end{array}\right\}^{T} \Phi^{\prime}
\end{aligned}
$$

Eq. (8a) can be written in a more compact form as

$$
\bar{\gamma}_{s z}(s, z)=\psi(s) \Phi^{\prime}(z)=\psi(s) \mathrm{K}_{X Y}(z)
$$

where the location of wall segments is represented as $s=(1),(2,1), \ldots(R),(R+1, R), \ldots(N, N$ $1),(N) . \psi$ is called the torsional function of a multi-cell closed-section.

Instead of assuming constant shear flow $N_{S Z} \approx N_{s z T}=G(s, z) t(s, z) \bar{\gamma}_{s z}(s, z)$ on each shell wall segment [2], the work [3,4] assumes a constant quantity $\bar{\gamma}_{s z} t$. The torsional function $\psi$ in the work $[3,4]$ therefore becomes:

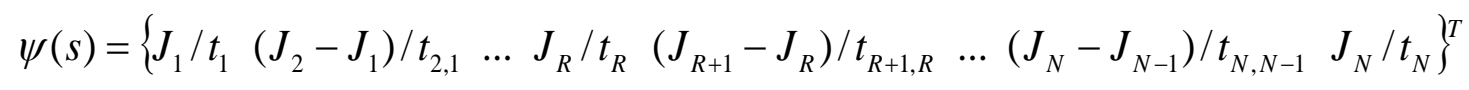

The $\delta$ integrations corresponding to Eqs. (4b,c,d) change to be

$$
\begin{aligned}
\delta_{R, R-1} & =\int_{R, R-1}(d s / t) \\
\delta_{R, R} & =\oint_{R, R}(d s / t) \\
\delta_{R, R+1} & =\int_{R, R+1}(d s / t)
\end{aligned}
$$

The mechanical meaning of constant quantity $\bar{\gamma}_{s z} t$ is unclear for composite materials.

Now, substituting Eq. (8b) into Eq. (1) gives the shell wall mid-surface axial warping displacement.

$$
\bar{w}_{\omega}(s, z)=-\omega(s) \Phi^{\prime}(z)
$$

where $\omega(s)=\eta(s)-C^{-1} \oint \eta d s$ is the warping function with $\eta(s)=\int_{0}^{s}[r(s)-\psi(s)] d s$. It has same form as that for single-cell cross section as expected. Then, the shell wall mid-surface axial strain $\bar{\varepsilon}_{z z}$ is expressed as in terms of the global beam strain and curvatures, which is the same as that in Eq. (18) in part 1 [1] and is recorded here.

$$
\bar{\varepsilon}_{z z}=\epsilon_{Z}+Y(s) K_{X}+X(s) K_{Y}+\omega(s) K_{\omega}
$$

The 1-D multi-cell TWCSCBs constitutive equations can then be established in the same way as that for the 1-D single-cell TWCSCBs by replacing the single-cell torsional function with the multi-cell ones given here. The details can be found in Eqs. (A18-32) in part 1[1] of 
the work.

The shell wall mid-surface shear strain $\bar{\gamma}_{s z}$ in Eq. (8b) and the axial strain $\bar{\varepsilon}_{z z}$ in Eq. (12) serve the basis for the mechanical modelling in the work [2-4]. It is worth to repeat the following point made in part 1 [1] of the present work. Eq. (8b) is the key feature in works [2$4]$ in which the material anisotropies in TWCSCBs are not considered. It gives the solution of the local shell wall mid-surface warping displacement $\bar{w}_{\omega}(s, z)$ in Eq. (11) which produces the local shell wall mid-surface warping axial strain $\omega(s) K_{\omega}$ in Eq. (12) and. The part 1 [1] of the present study has proved that $\omega(s) K_{\omega}$ has small effect on the modelling accuracy. Hence, the axial strain in Eq. (12) is kept in use in the present work although a slightly more accurate approach can be achieved with much more complications to use the $\bar{\gamma}_{s z}$ determined in next section. Part 1 [1] of the present study has shown that the adoption of Eq. (8b) can introduce gross error on $\bar{\gamma}_{s z}$ and consequently on the accuracy of modelling. In next section the $\bar{\gamma}_{s z}$ will be determined by using the material constitutive laws of local shell wall.

\section{The present TWCSCBs model}

From the constitutive equations of local shell wall given in Eq. (22) or (23) in part 1 [1], the shell wall mid-surface shear strain $\bar{\gamma}_{s z}$ reads

$$
\bar{\gamma}_{s z}=S_{41} \bar{\varepsilon}_{z z}+S_{42} \bar{k}_{z z}+S_{43} \bar{k}_{s z}+S_{44} N_{s z}
$$

where $S_{i j}$ are given in Appendix Eq. (A2) of part 1 [1]. Substituting Eq. (13) into Eq. (1) gives,

$$
\oint_{R}\left(S_{41} \bar{\varepsilon}_{z z}+S_{42} \bar{\kappa}_{z z}+S_{43} \bar{\kappa}_{s z}+S_{44} N_{s z}\right) d s=2 A_{e R} \mathrm{~K}_{X Y}
$$

The resultant shear force $N_{s z}$ can be considered in two parts, namely the constant St.Venant torsional shear flow $N_{s z T}$ and the variable bending shear flow $N_{s z B}$, i.e. $N_{s z}=N_{s z T}+N_{s z B}$. Then, Eq. (14) becomes,

$$
\oint_{R}\left(S_{41} \bar{\varepsilon}_{z z}+S_{42} \bar{\kappa}_{z z}+S_{43} \bar{\kappa}_{s z}+S_{44} N_{s z T}+S_{44} N_{s z B}\right) d s=2 A_{e R} K_{X Y}
$$

Since $\oint_{R}\left(S_{44} N_{s z B}\right) d s=0$ for symmetrical cross-section and negligibly small for most of the closed-cross sections in common applications, $N_{s z T}$ can be solved from Eq (15) by neglecting the bending shear term $\oint_{R}\left(S_{44} N_{s z B}\right) d s$

$$
\oint_{R}\left(S_{44} N_{s z T}\right) d s=2 A_{e R} K_{X Y}-\oint_{R}\left(S_{41} \bar{\varepsilon}_{z z}\right) d s-\oint_{R}\left(S_{42} \bar{\kappa}_{z z}\right) d s-\oint_{R}\left(S_{43} \bar{\kappa}_{s z}\right) d s
$$

Replacing $N_{s z T}$ by shear flow $q$ for simplicity, the left-hand side of Eq. (16) can be considered for each wall segment as: 


$$
\oint_{R} S_{44} N_{s z T} d s=\left(-q_{R-1} \delta_{R, R-1}+q_{R} \delta_{R, R}-q_{R+1} \delta_{R, R+1}\right)
$$

where:

$$
\begin{aligned}
\delta_{R, R-1} & =\int_{R, R-1} S_{44} d s \\
\delta_{R, R} & =\oint_{R} S_{44} d s \\
\delta_{R, R+1} & =\int_{R, R+1} S_{44} d s
\end{aligned}
$$

Using Eq. (12) for $\bar{\varepsilon}_{z z}$ and $\bar{k}_{z z}, \bar{k}_{s z}$ in Eq. (8) in part 1 [1], the left hand side of Eq. (16a) becomes,

$$
\begin{aligned}
& 2 A_{e R} \mathrm{~K}_{X Y}-\oint_{R}\left(S_{41} \bar{\varepsilon}_{z z}\right) d s-\oint_{R}\left(S_{42} \bar{\kappa}_{z z}\right) d s-\oint_{R}\left(S_{43} \bar{\kappa}_{s z}\right) d s \\
& =\in_{z}\left(\oint_{R} S_{14} d s\right)+\mathrm{K}_{X}\left(\oint_{R}\left(S_{14} Y-S_{24} \cos \alpha\right) d s\right)+\mathrm{K}_{Y}\left(\oint_{R}\left(S_{14} X+S_{24} \sin \alpha\right) d s\right) \\
& +\mathrm{K}_{X Y}\left(2 \oint_{R} S_{34} d s+2 A_{e R}\right)+\mathrm{K}_{\omega}\left(\oint_{R}\left(S_{14} \omega-S_{24} q\right) d s\right)
\end{aligned}
$$

Note that the quantity $q$ in Eq. (16f) is the normal distance from the global axis $O Z$ to an arbitrary point $(s, z)$ on the shell wall mid-surface as shown in Fig. 1 in part 1 [1]. Now, assembling Eq. (16) for all the $N$ cells shown in Fig. 1 gives

$$
[\delta]\{q\}=[P]\{\varepsilon\}
$$

where

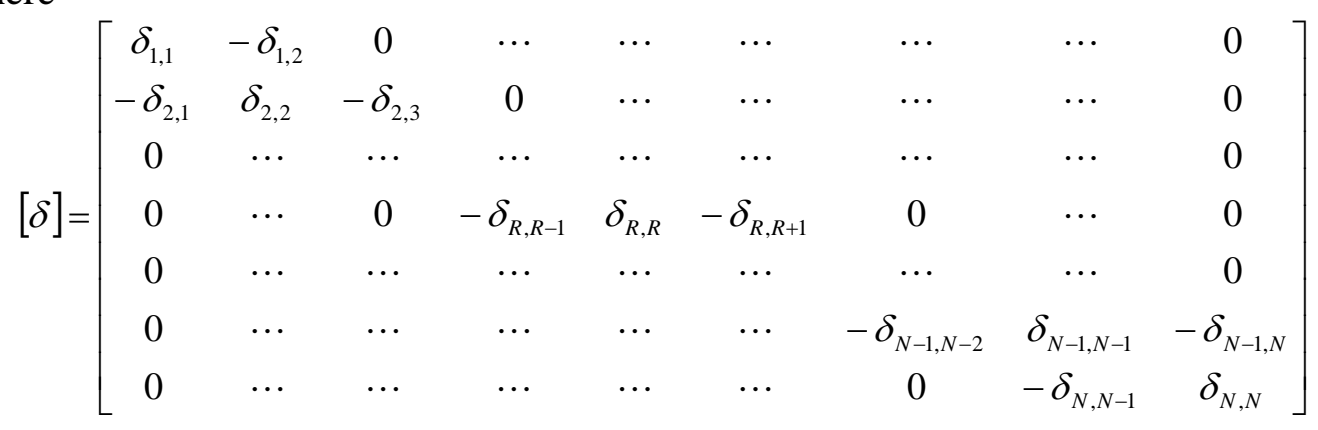

$[P]=\left[\begin{array}{ccccc}\oint_{1} S_{14} d s & \oint_{1}\left(S_{14} Y-S_{24} \cos \alpha\right) d s & \oint_{1}\left(S_{14} X+S_{24} \sin \alpha\right) d s & 2 \oint_{1} S_{34} d s+2 A_{e R} & \oint_{1}\left(S_{14} \omega-S_{24} q\right) d s \\ \vdots & \vdots & \vdots & \vdots & \vdots \\ \oint_{R} S_{14} d s & \oint_{R}\left(S_{14} Y-S_{24} \cos \alpha\right) d s & \oint_{R}\left(S_{14} X+S_{24} \sin \alpha\right) d s & 2 \oint_{R} S_{34} d s+2 A_{e R} & \oint_{R}\left(S_{14} \omega-S_{24} q\right) d s \\ \vdots & \vdots & \vdots & \vdots & \vdots \\ \oint_{N} S_{14} d s & \oint_{N}\left(S_{14} Y-S_{24} \cos \alpha\right) d s & \oint_{N}\left(S_{14} X+S_{24} \sin \alpha\right) d s & 2 \oint_{N} S_{34} d s+2 A_{e R} & \oint_{N}\left(S_{14} \omega-S_{24} q\right) d s\end{array}\right]$

$$
\{\varepsilon\}=\left\{\begin{array}{lllll}
\in_{z} & \mathrm{~K}_{X} & \mathrm{~K}_{Y} & \mathrm{~K}_{X Y} & \mathrm{~K}_{\omega}
\end{array}\right\}^{T}
$$


The shear flow developed in each cell $\{q\}$ is then solved in terms of the global strain and curvatures $\{\varepsilon\}$. That is

$$
\{q\}=[\zeta]\{\varepsilon\}
$$

where

$$
[\zeta]=[\delta]^{-1}[P]
$$

Finally, the shear flow distribution in each wall can be calculated as:

$$
\left\{\begin{array}{c}
q_{1} \\
q_{2,1} \\
\vdots \\
q_{R} \\
q_{R+1, R} \\
\vdots \\
q_{N, N-1} \\
q_{N}
\end{array}\right\}=\left[\begin{array}{c}
\left\{\zeta_{1, j}\right\} \\
\left\{\zeta_{2, j}\right\}-\left\{\zeta_{1, j}\right\} \\
\vdots \\
\left\{\zeta_{R, j}\right\} \\
\left\{\zeta_{R+1, j}\right\}-\left\{\zeta_{R, j}\right\} \\
\vdots \\
\left\{\zeta_{N, j}\right\}-\left\{\zeta_{N-1, j}\right\} \\
\left\{\zeta_{N, j}\right\}
\end{array}\right]\{\varepsilon\}
$$

where $\left\{\zeta_{R, j}\right\}(j=1,2, \ldots, 5)$ is the $R_{t h}$ row of the matrix $[\zeta]$. Replacing the shear flow symbol $q$ by the symbol $N_{s z}$ used in local shell wall constitutive equations, the constant shear flow at each wall segment is given as:

$$
N_{s z T}(s)=\left(\xi_{s, 1}\right) \epsilon_{z}+\left(\xi_{s, 2}\right) K_{X}+\left(\xi_{s, 3}\right) K_{Y}+\left(\xi_{s, 4}\right) K_{X Y}+\left(\xi_{s, 5}\right) K_{\omega}
$$

The location of the wall segment is $s=(1),(2,1), \ldots(R), \quad(R+1, R), \ldots(N, N-1),(N)$ corresponding to Eq. (19), and $\xi_{s, j}(j=1,2, \ldots, 5)$ can be easily calculated from Eq. (19) using the matrix $[\zeta]$ in Eq. (18b). Now, substituting Eq. (20) in to Eq. (13) and neglecting bending shear flow give the shell wall mid-surface shear strain $\bar{\gamma}_{s z}$. Finally, the 1-D multi-cell TWCSCBs constitutive equations can then be established in the same way as that for the 1-D single-cell TWCSCBs in part 1 [1] of the work. That is,

$$
\left\{\begin{array}{lllll}
F_{Z} & M_{X} & M_{Y} & M_{Z} & M_{\omega}
\end{array}\right\}^{T}=\left[E_{i j}\right]\left\{\in_{Z} \quad K_{X} \quad K_{Y} \quad K_{X Y} \quad K_{\omega}\right\}^{T}
$$

The details of the stiffness matrix $\left[E_{i j}\right]$ are given in the Appendix.

\section{Numerical validations}

The 1-D multi-cell TWCSCB model in Eq. (21) has been implemented in a 1-D beam finite element similar to that in the work [3,4]. For the purpose of convenient comparison, the model in the work [2,3,4] and the present model are designated as Model 1 and 2 in the 
following text, respectively. The numerical results calculated from both models are compared with results from an ABAQUS shell model. The four-node linear quad-4 S4R5 shell element from ABAQUS element library is employed [6].

The first validation example concerns a three-cell cantilever box beam as shown in Fig. 2 . The box beam consists of three equal cells. The material properties are summarized as

$$
E_{1}=148 G P a, E_{2}=9.65 G P a, G_{12}=4.55 G P a, v_{12}=0.3
$$

Similar to that in part 1[1] of the work, four loading cases are considered. They are the axial load $F_{Z}$, two transverse loads $F_{X}, F_{Y}$ and torsional moment $M_{Z}$. The loads are applied individually at the free end of the box. Five different layups are studied. They are layups in [5] $\left[45^{\circ} / 90^{0}\right],\left[60^{0} / 70^{\circ} / 80^{0}\right]$, symmetric layups $\left[-75^{0} / 75^{0}\right]_{\mathrm{s}}$, anti-symmetric layups $\left[70^{0} /-20^{0}\right]_{2}$ and quasi isotropic layups $\left[75^{\circ} / 90^{\circ} /-75^{\circ}\right]$. Note that all the layups are counted in the LSWCS $n s z$ from $n=-t / 2$ and the fibre angle $\theta$ in Fig. 1 of part 1 [1] of the work is measured relative to $s$ and not the usual axial axis $z$. The direction of $s$ axis is anti-clockwise along the skin shell wall and downwards and upwards along the left and right webs, respectively. Table 1 shows the free end displacements and rotations from both models and the four-node linear quad-4 S4R5 shell element from ABAQUS. For symmetric and quasi-isotropic laminate layups, the results predicted by both models are identical and compares well with ABAQUS simulations. For layups [45/90], the difference between the two models becomes clearly visible but not significant. Model 2 achieves better accuracy than Model 1 comparing with the ABAQUS benchmark. For arbitrary layups [60/70/80] and antisymmetric layup [70/-20]2, Model 2 achieves consistently close agreement with ABAQUS whereas gross errors are found in Model 1.

The failure of Model 1 can be seen as a consequence of its inappropriate application of the shell wall mid-surface shear strain in Eq. (8) to a composite beam. The shear strain $\bar{\gamma}_{s z}$ for a composite beam should be explicitly defined by Eq. (13) indicating that the shear strain $\bar{\gamma}_{s z}$ of a composite shell is not only related with shear flow $N_{s z}$ but also depends on the material coupling with axial strain $\bar{\varepsilon}_{z z}$, and curvatures $\bar{k}_{z z}$ and $\bar{k}_{\mathrm{sz}}$.

The causes of significant errors in calculating the bending stiffness are similar to those observed in the analysis of the single-cell TWCSCBs in part 1 [1] of the work. The $A_{16}$ and $A_{26}$ decide the magnitude of $k_{12}$ and $k_{23}$, which ultimately affect the magnitude of $\Delta E_{22}$ and $\Delta E_{33}$. Unlike the single-cell TWCSCBs of which axial, axial-twist coupling and torsional stiffnesses were unchanged between the Model 1 and 2 regardless of laminated layups, the axial, axial-twist coupling and torsional stiffnesses of the multi-cell box beam varies between the two models for different laminate layups, as shown in Table 1. Assessments of the stiffness difference, e.g. $\Delta E_{11}$ and $\Delta E_{44}$, can be carried out in the similar approach as $\Delta E_{22}$ and $\Delta E_{33}$ from part 1 [1] of the work for single-cell TWCSCB model. The $\Delta E_{11}$ is studied as a demonstration example below.

The constitutive relationship between the global axial force $F_{Z}$ and the global axial strain $\epsilon_{Z}$ in Model 1 is defined by the stiffness term $E_{11}$ given as 


$$
\left(E_{11}\right)_{M 1}=\oint k_{11} d s
$$

where the subscript $M 1$ denotes Model 1. Its counterpart in the present model is given as

$$
\left(E_{11}\right)_{M 2}=\oint k_{11} d s+\oint-k_{12}^{2} / k_{22} d s+\oint S_{14} \xi_{s, 1} d s=\left(E_{11}\right)_{M 1}+R_{Z}
$$

where the underlined part is the difference between the two models and is represented by $R_{Z}$ as

with

$$
R_{\mathrm{Z}}=R_{\mathrm{Z} 1}+R_{\mathrm{Z} 2}
$$

$$
\begin{gathered}
R_{\mathrm{Z} 1}=\oint-k_{12}^{2} / k_{22} d s \\
R_{\mathrm{Z} 2}=\oint S_{14} \xi_{s, 1} d s
\end{gathered}
$$

Table 2 lists the stiffness parameters and variations of the axial stiffness between the two models for the five layups considered. Upon comparisons, the following observations were obtained:

- Generally, $\Delta E_{11}$ due to terms $R_{\mathrm{Z} 1}$ and $R_{\mathrm{Z} 2}$ are less significant compared to the $\Delta E_{22}$ and $\Delta E_{33}$ given in Table 2 of part 1 [1] of the work. The material coupling between $\bar{\gamma}_{s z}$ and $\bar{\varepsilon}_{z z}$ are mainly contributed to the warping which is negligible for closed cross section beams.

- For symmetrical layups and quasi-isotropic layup, $A_{16}=A_{26}=0$. Effectively, $k_{12}=S_{14}=0$. Therefore, $R_{Z}$ vanishes so that the axial displacements calculated by the two models are identical.

- For layup [45/90], the $k_{12}$ is much smaller than $k_{22}$. As a result, the magnitude of $R_{z}$ become insignificant compared to $E_{11}$ from Model 1 . Therefore, the difference of the axial stiffness of the two models is small.

- For arbitrary layups [80/70/60] and [70/-20] 2 where the $k_{12}$ is much greater than $k_{22}$, the $R_{Z}$ is greater than $4 \%$ of $E_{11}$ from Model 1 and need to be considered.

To validate present model on a commonly used multi-cell TWCSCB with curved walls, a cantilever multi-cell elliptical beam with same material properties and layups as those used for multi-cell box beam is assessed. Fig. 3 shows the geometrical specifications of the beam. The results from both models are tabulated in Table 3 along with ABAQUS simulations. The observations are the same as those concluded from the analysis of the three-cell box beam.

\section{Conclusions}

The accurate structure mechanical model for single-cell TWCSCBs in part 1 [1] of the work is extended to multi-cell TWCSCBs. Numerical comparisons with ABAQUS simulations are performed for box and cylindrical beams with a variety of laminate layups under various loading conditions and excellent agreements are observed. It concludes that the present model is applicable with truly arbitrary layups of laminates. Neglecting the effect of material anisotropies can lead to gross overestimate of global beam bending stiffness while neglecting the axial warping effect leads to slight overestimate of the global beam extension 
and torsional stiffness. It will be valuable work to extend the present model to broader areas such as including vibration analysis [7], transverse shear effect [8], geometrical nonlinearity [9], and etc.

\section{Appendix}

Elements of the global cylinder beam stiffness matrix $\left[E_{i j}\right]=\left[E_{i j}\right]^{T}$ in Eq. (21) in the present model

$$
\begin{aligned}
& \left.\left\{\begin{array}{lllll}
F_{Z} & M_{X} & M_{Y} & M_{Z} & M_{\omega}
\end{array}\right\}^{T}=\left[E_{i j}\right]\right\}\left\{\begin{array}{lllll}
\epsilon_{Z} & K_{X} & K_{Y} & K_{X Y} & K_{\omega}
\end{array}\right\}^{T}: \\
& E_{11}=\oint S_{11} d s+\oint S_{14} \xi_{s, 1} d s \\
& E_{12}=\oint\left(S_{11} Y-S_{12} \cos \alpha\right) d s+\oint S_{14} \xi_{s, 2} d s \\
& E_{13}=\oint\left(S_{11} X+S_{12} \sin \alpha\right) d s+\oint S_{14} \xi_{s, 3} d s \\
& E_{14}=\oint\left(2 S_{13}\right) d s+\oint S_{14} \xi_{s, 4} d s \\
& E_{15}=\oint\left(S_{11} \omega-S_{12} q\right) d s+\oint S_{14} \xi_{s, 5} d s \\
& E_{22}=\oint\left(S_{11} Y^{2}-S_{12} Y \cos \alpha\right) d s+\oint S_{14} Y \xi_{s, 2} d s \\
& -\left(\oint\left(S_{12} Y \cos \alpha-S_{22} \cos ^{2} \alpha\right) d s+\oint S_{24} \cos \alpha \xi_{s, 2} d s\right) \\
& E_{23}=\oint\left(S_{11} X Y+S_{12} Y \sin \alpha\right) d s+\oint S_{14} Y \xi_{s, 3} d s \\
& -\left(\oint\left(S_{12} X \cos \alpha+S_{22} \cos \alpha \sin \alpha\right) d s+\oint S_{24} \cos \alpha \xi_{s, 3} d s\right) \\
& E_{24}=\oint\left(2 S_{13} Y\right) d s+\oint S_{14} Y \xi_{s, 4} d s-\left(\oint\left(2 S_{23} \cos \alpha\right) d s-\oint S_{24} \cos \alpha \xi_{s, 4} d s\right) \\
& E_{25}=\oint\left(S_{11} Y \omega-S_{12} Y q\right) d s+\oint S_{14} Y \xi_{s, 5} d s \\
& -\left(\oint\left(S_{12} \cos \alpha \omega-S_{22} \cos \alpha q\right) d s+\oint S_{24} \cos \alpha \xi_{s, 5} d s\right) \\
& E_{33}=\oint\left(S_{11} X^{2}+S_{12} X \sin \alpha\right) d s+\oint S_{14} X \xi_{s, 3} d s \\
& +\left(\oint\left(S_{12} X \sin \alpha+S_{22} \sin ^{2} \alpha\right) d s+\oint S_{24} \sin \alpha \xi_{s, 3} d s\right) \\
& E_{34}=\oint\left(2 S_{13} X\right) d s+\oint S_{14} X \xi_{s, 4} d s+\left(\oint\left(2 S_{23} \sin \alpha\right) d s+\oint S_{24} \sin \alpha \xi_{s, 4} d s\right)
\end{aligned}
$$




$$
\begin{aligned}
E_{35}= & \oint\left(S_{11} X \omega-S_{12} X q\right) d s+\oint S_{14} X \xi_{s, 5} d s \\
& +\left(\oint\left(S_{12} \sin \alpha \omega-S_{22} \sin \alpha q\right) d s+\oint S_{24} \sin \alpha \xi_{s, 5} d s\right) \\
E_{44}= & \oint r \xi_{s, 4} d s+\left(\oint\left(4 S_{33}\right) d s+\oint 2 S_{34} \xi_{s, 4} d s\right) \\
E_{45}= & \oint r \xi_{s, 5} d s+\left(\oint_{s}\left(2 S_{13} \omega-2 S_{23} q\right) d s+\oint 2 S_{34} \xi_{s, 5} d s\right) \\
E_{55}= & \oint\left(S_{11} \omega^{2}-S_{12} \omega q\right) d s+\oint S_{14} \omega \xi_{s, 5} d s-\left(\oint\left(S_{12} \omega q-S_{22} q^{2}\right) d s+\oint S_{24} q \xi_{s, 5} d s\right)
\end{aligned}
$$

\section{References}

[1] Zhang C, Wang S. Structure mechanical modeling of thin-walled closed-section composite beams, part 1: single-cell cross section. Composite Structures 2013 (submitted).

[2] Librescu L, Song O. Thin-Walled Composite Beams: Theory and Application. Berlin: Springer; 2006.

[3] Lee J, Lee S. Flexural-torsional behavior of thin-walled composite beams. ThinWalled Structures 2004;42(9):1293-305.

[4] Vo TP, Lee J. Flexural-torsional behavior of thin-walled closed-section composite box beams. Eng.Struct. 2007;29(8):1774-82.

[5] Kollar LP, Pluzsik A. Analysis of Thin-Walled Composite Beams with Arbitrary Layup. Journal of Reinforced Plastics and Composites 2002 November 01;21(16):1423-65.

[6] Simulia. ABAQUS/Standard User's Manual. 2009;version 6.9.

[7] Vo TP, Lee J. Free vibration of thin-walled composite box beams. Composite Structures 2008;84(1):11-20.

[8] Vo TP, Lee J. Flexural-torsional behavior of thin-walled composite box beams using shear-deformable beam theory. Eng. Struct. 2008;30(7):1958-68.

[9] Vo TP, Lee J. Geometrically nonlinear theory of thin-walled composite box beams using shear-deformable beam theory. Int.J.Mech.Sci. 2010;52(1):65-74. 


\section{Figure captions:}

Fig. 1. A multi-cell cross section with its shear flow under pure torque $M_{Z}$.

Fig. 2. Dimensions of a cantilever thin-walled composite three-cell box beam.

Fig. 3. Dimensions of a cantilever thin-walled composite three-cell elliptical beam. 


\section{Table captions:}

Table 1 Comparions of free end displacements of cantilever thin-walled composite three-cell box beams.

Table 2 Stiffness parameters of the shell wall for the composite three-cell box beams.

Table 2 Comparions of free end displacements of cantilever thin-walled composite three-cell elliptical beams. 


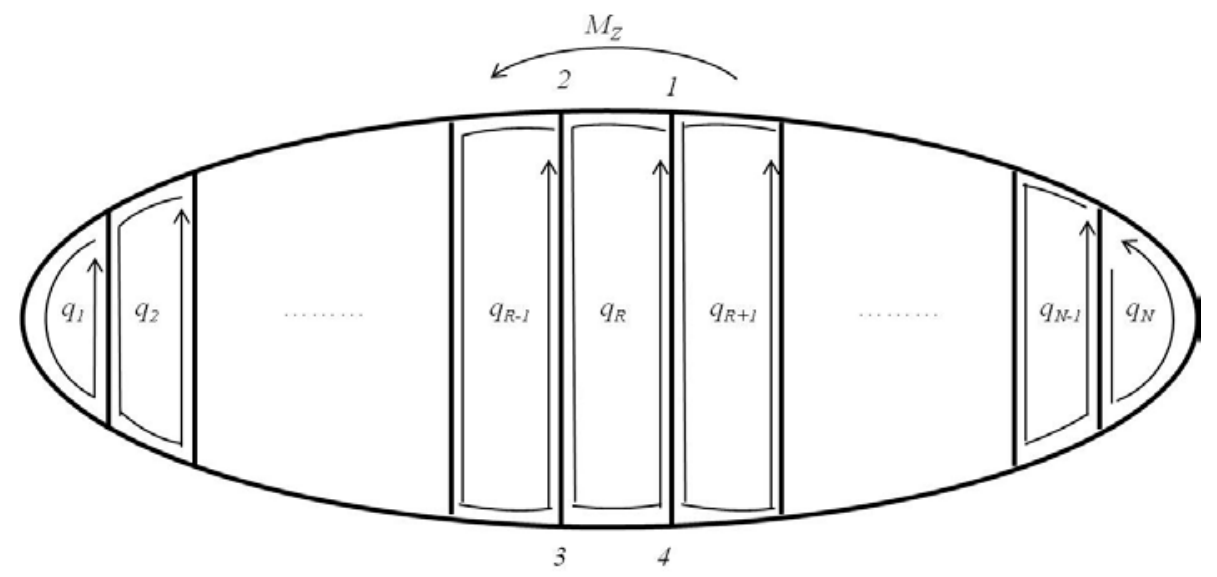

Fig. 1. A multi-cell cross section with its shear flow under pure torque $M_{Z}$. 


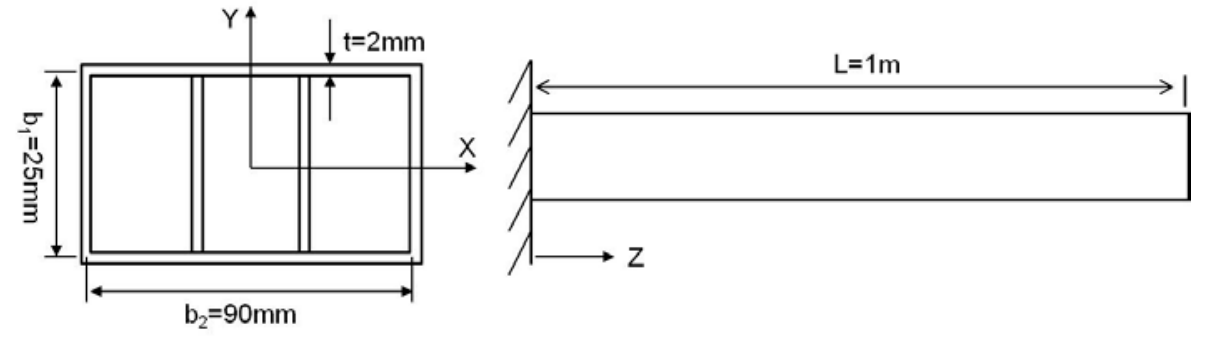

Fig. 2. Dimensions of a cantilever thin-walled composite three-cell box beam. 


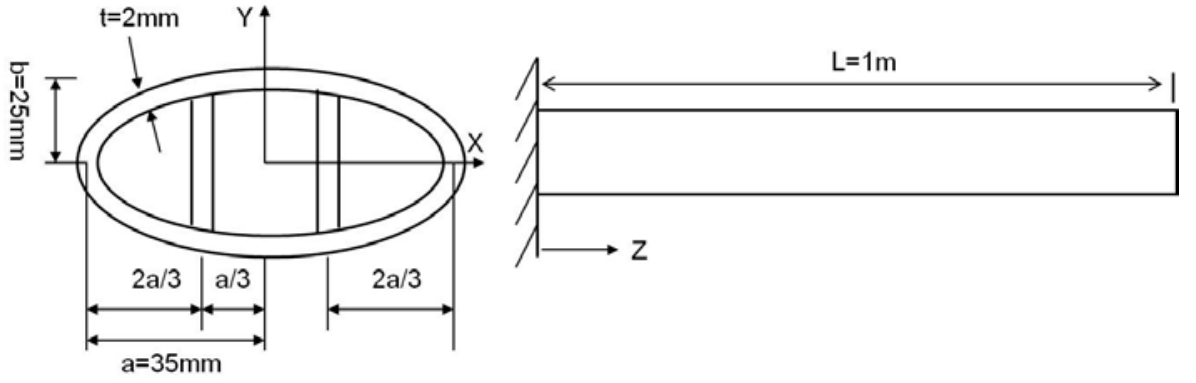

Fig. 3. Dimensions of a cantilever thin-walled composite three-cell elliptical beam. 
Table 1 Comparions of free end displacements of cantilever thin-walled composite three-cell box beams.

\begin{tabular}{|c|c|c|c|c|c|c|c|}
\hline \multirow[b]{2}{*}{ Load Case } & \multirow[b]{2}{*}{ Disp } & \multirow[b]{2}{*}{ Models } & \multicolumn{2}{|c|}{ Layups in [5] } & \multirow{2}{*}{$\begin{array}{c}\text { symmetric } \\
{[-75 / 75]_{s}}\end{array}$} & \multirow{2}{*}{$\begin{array}{c}\text { Anti } \\
\text { symmetric } \\
{[70 /-20]_{2}}\end{array}$} & \multirow{2}{*}{$\begin{array}{c}\text { Quasi } \\
\text { isotropic } \\
\text { [75/90/-75] }\end{array}$} \\
\hline & & & [45/90] & {$[60 / 70 / 80]$} & & & \\
\hline & & ABAQUS & 3.89E-04 & $6.13 \mathrm{E}-04$ & 2.64E-04 & 9.36E-04 & $2.44 \mathrm{E}-04$ \\
\hline & $W, \mathrm{~m}$ & Model 1 & 3.89E-04 & 5.71E-04 & $2.65 \mathrm{E}-04$ & 8.75E-04 & 2.43E-04 \\
\hline & & Model 2 & 3.90E-04 & $6.15 \mathrm{E}-04$ & 2.65E-04 & $9.43 \mathrm{E}-04$ & 2.43E-04 \\
\hline \multicolumn{8}{|l|}{$\mathrm{F}_{\mathrm{Z}}=2.4 \mathrm{kN}$} \\
\hline & & ABAQUS & $-6.21 \mathrm{E}-03$ & $-3.62 \mathrm{E}-02$ & $0.00 \mathrm{E}+00$ & $-4.42 \mathrm{E}-02$ & 7.75E-04 \\
\hline & $\Phi$, rads & Model 1 & $-6.06 \mathrm{E}-03$ & -3.36E-02 & $0.00 \mathrm{E}+00$ & -4.17E-02 & 8.04E-04 \\
\hline & & Model 2 & $-6.09 E-03$ & $-3.62 \mathrm{E}-02$ & $0.00 \mathrm{E}+00$ & $-4.49 \mathrm{E}-02$ & 8.04E-04 \\
\hline \multirow{3}{*}{$\mathrm{F}_{\mathrm{Y}}=150 \mathrm{~N}$} & \multirow{3}{*}{$V, \mathrm{~m}$} & ABAQUS & $2.00 \mathrm{E}-03$ & 3.26E-03 & 1.39E-03 & 5.29E-03 & $1.30 \mathrm{E}-03$ \\
\hline & & Model 1 & 1.91E-03 & 1.70E-03 & 1.36E-03 & 2.69E-03 & $1.25 \mathrm{E}-03$ \\
\hline & & Model 2 & $1.96 \mathrm{E}-03$ & $3.25 \mathrm{E}-03$ & $1.36 \mathrm{E}-03$ & 5.34E-03 & $1.25 \mathrm{E}-03$ \\
\hline \multirow{3}{*}{$F_{X}=150 N$} & \multirow{3}{*}{$U, \mathrm{~m}$} & ABAQUS & $9.13 \mathrm{E}-04$ & 1.16E-03 & $6.40 \mathrm{E}-04$ & 1.79E-03 & $6.06 \mathrm{E}-04$ \\
\hline & & Model 1 & 8.56E-04 & 7.59E-04 & 6.06E-04 & 1.19E-03 & 5.55E-04 \\
\hline & & Model 2 & 8.70E-04 & 1.07E-03 & $6.06 \mathrm{E}-04$ & $1.70 \mathrm{E}-03$ & 5.55E-04 \\
\hline \multirow{3}{*}{$\mathrm{M}_{\mathrm{Z}}=100 \mathrm{~N} . \mathrm{m}$} & \multirow{3}{*}{$\Phi$, rads } & ABAQUS & $1.68 \mathrm{E}-02$ & 2.04E-02 & $1.29 \mathrm{E}-02$ & 2.06E-02 & $1.64 \mathrm{E}-02$ \\
\hline & & Model 1 & 1.70E-02 & 1.99E-02 & $1.30 \mathrm{E}-02$ & 2.02E-02 & $1.66 \mathrm{E}-02$ \\
\hline & & Model 2 & $1.71 \mathrm{E}-02$ & 2.05E-02 & 1.30E-02 & 2.09E-02 & 1.66E-02 \\
\hline
\end{tabular}


Table 2 Stiffness parameters of the shell wall for the composite three-cell box beams.

\begin{tabular}{|c|c|c|c|c|c|}
\hline \multirow{2}{*}{$\begin{array}{c}\text { Stiffness } \\
\text { parameters }\end{array}$} & \multicolumn{2}{|c|}{ Layups in [5] } & \multirow{2}{*}{$\begin{array}{l}\text { symmetric } \\
{[75 /-75]_{s}}\end{array}$} & \multirow{2}{*}{$\begin{array}{c}\text { Anti } \\
\text { symmetric } \\
{[70 /-20]_{2}} \\
\end{array}$} & \multirow{2}{*}{$\begin{array}{c}\text { Quasi } \\
\text { isotropic } \\
{[75 / 90 /-75]}\end{array}$} \\
\hline & {$[45 / 90]$} & {$[60 / 70 / 80]$} & & & \\
\hline$A_{16}$ & $3.479 \mathrm{E}+07$ & $1.497 \mathrm{E}+07$ & $0.000 \mathrm{E}+00$ & $-3.313 \mathrm{E}+07$ & $0.000 \mathrm{E}+00$ \\
\hline$A_{26}$ & $3.479 \mathrm{E}+07$ & $7.089 \mathrm{E}+07$ & $0.000 \mathrm{E}+00$ & $3.313 \mathrm{E}+07$ & $0.000 \mathrm{E}+00$ \\
\hline$k_{12}$ & $9.990 \mathrm{E}+06$ & $5.213 \mathrm{E}+07$ & $0.000 \mathrm{E}+00$ & $4.164 \mathrm{E}+07$ & $0.000 \mathrm{E}+00$ \\
\hline$k_{22}$ & $2.087 \mathrm{E}+07$ & $2.968 \mathrm{E}+07$ & $2.592 \mathrm{E}+07$ & $2.851 E+07$ & $2.031 \mathrm{E}+07$ \\
\hline$R_{Z 1}$ & $-1.82 \mathrm{E}+06$ & $-3.48 \mathrm{E}+07$ & $0.00 \mathrm{E}+00$ & $-2.31 \mathrm{E}+07$ & $0.00 \mathrm{E}+00$ \\
\hline$R_{\mathrm{Z} 2}$ & $1.66 \mathrm{E}+06$ & $3.19 \mathrm{E}+07$ & $0.00 \mathrm{E}+00$ & $2.12 \mathrm{E}+07$ & $0.00 \mathrm{E}+00$ \\
\hline$R_{Z}$ & $-1.53 \mathrm{E}+05$ & $-2.93 \mathrm{E}+06$ & $0.00 \mathrm{E}+00$ & $-1.95 \mathrm{E}+06$ & $0.00 \mathrm{E}+00$ \\
\hline$\left(E_{11}\right)_{\mathrm{M} 1}$ & $6.32 \mathrm{E}+07$ & $7.18 \mathrm{E}+07$ & $9.05 \mathrm{E}+07$ & $4.64 \mathrm{E}+07$ & $9.88 \mathrm{E}+07$ \\
\hline$\Delta E_{11}$ & $-0.24 \%$ & $-4.09 \%$ & $0.00 \%$ & $-4.20 \%$ & $0.00 \%$ \\
\hline
\end{tabular}


Table 3 Comparions of free end displacements of cantilever thin-walled composite three-cell elliptical beams.

\begin{tabular}{|c|c|c|c|c|c|c|c|}
\hline \multirow[b]{2}{*}{ Load Case } & \multirow[b]{2}{*}{ Disp } & \multirow[b]{2}{*}{ Models } & \multicolumn{2}{|c|}{ Layups in [5] } & \multirow{2}{*}{$\begin{array}{c}\text { symmetric } \\
{[-75 / 75]_{\mathrm{s}}}\end{array}$} & \multirow{2}{*}{$\begin{array}{c}\text { Anti } \\
\text { symmetric } \\
{[70 /-20]_{2}}\end{array}$} & \multirow{2}{*}{$\begin{array}{c}\text { Quasi } \\
\text { isotropic } \\
{[75 / 90 /-75]}\end{array}$} \\
\hline & & & [45/90] & {$[60 / 70 / 80]$} & & & \\
\hline \multirow{7}{*}{$\mathrm{F}_{\mathrm{Z}}=2.4 \mathrm{kN}$} & \multirow{3}{*}{$W, \mathrm{~m}$} & ABAQUS & $5.21 \mathrm{E}-04$ & 8.03E-04 & $3.54 \mathrm{E}-04$ & $1.23 \mathrm{E}-03$ & $3.26 \mathrm{E}-04$ \\
\hline & & Model 1 & 5.19E-04 & 7.46E-04 & 3.55E-04 & $1.14 \mathrm{E}-03$ & $3.25 \mathrm{E}-04$ \\
\hline & & Model 2 & $5.21 \mathrm{E}-04$ & 8.07E-04 & 3.55E-04 & $1.23 \mathrm{E}-03$ & $3.25 \mathrm{E}-04$ \\
\hline & \multirow{4}{*}{$\Phi$, rads } & & & & & & \\
\hline & & ABAQUS & -9.37E-03 & -5.38E-02 & $0.00 \mathrm{E}+00$ & $-6.65 \mathrm{E}-02$ & $1.20 \mathrm{E}-03$ \\
\hline & & Model 1 & $-9.18 E-03$ & $-4.99 \mathrm{E}-02$ & $0.00 \mathrm{E}+00$ & $-6.15 E-02$ & $1.44 \mathrm{E}-03$ \\
\hline & & Model 2 & $-9.23 \mathrm{E}-03$ & $-5.41 \mathrm{E}-02$ & $0.00 \mathrm{E}+00$ & $-6.66 \mathrm{E}-02$ & $1.44 \mathrm{E}-03$ \\
\hline \multirow{3}{*}{$F_{Y}=150 N$} & \multirow{3}{*}{$V, \mathrm{~m}$} & ABAQUS & $3.74 \mathrm{E}-03$ & 6.09E-03 & 2.61E-03 & $1.00 \mathrm{E}-02$ & $2.43 \mathrm{E}-03$ \\
\hline & & Model 1 & 3.59E-03 & $3.20 \mathrm{E}-03$ & 2.57E-03 & 5.09E-03 & 2.35E-03 \\
\hline & & Model 2 & $3.68 \mathrm{E}-03$ & $6.10 \mathrm{E}-03$ & $2.57 \mathrm{E}-03$ & $1.01 \mathrm{E}-02$ & $2.35 \mathrm{E}-03$ \\
\hline \multirow{3}{*}{$F_{X}=150 N$} & \multirow{3}{*}{$U, \mathrm{~m}$} & ABAQUS & $2.58 \mathrm{E}-03$ & 3.50E-03 & $1.81 \mathrm{E}-03$ & $5.66 \mathrm{E}-03$ & $1.68 \mathrm{E}-03$ \\
\hline & & Model 1 & 2.45E-03 & 2.19E-03 & 1.76E-03 & 3.47E-03 & $1.61 \mathrm{E}-03$ \\
\hline & & Model 2 & $2.50 \mathrm{E}-03$ & 3.42E-03 & 1.76E-03 & $5.54 \mathrm{E}-03$ & $1.61 \mathrm{E}-03$ \\
\hline \multirow{3}{*}{$\mathrm{M}_{\mathrm{Z}}=100 \mathrm{~N} \cdot \mathrm{m}$} & \multirow{3}{*}{$\Phi$, rads } & ABAQUS & 3.03E-02 & 3.58E-02 & 2.33E-02 & 3.64E-02 & 2.97E-02 \\
\hline & & Model 1 & 3.07E-02 & 3.48E-02 & 2.32E-02 & 3.53E-02 & 2.96E-02 \\
\hline & & Model 2 & 3.08E-02 & 3.60E-02 & 2.32E-02 & 3.64E-02 & 2.96E-02 \\
\hline
\end{tabular}

